\title{
Increasing Smoke Classifier Accuracy using Naïve Bayes Method on Internet of Things
}

\author{
Alieja Muhammad Iqbal ${ }^{* 1}$, Maman Abdurohman ${ }^{2}$, Aji Gautama Putrada ${ }^{3}$ \\ 1,2Universitas Telkom/School of Computing \\ aliejaaa@student.telkomuniversity.ac.id ${ }^{* 1}$, abdurohman@telkomuniversity.ac.id ${ }^{2}$, \\ ajigps@telkomuniversity.ac.id ${ }^{3}$
}

\begin{abstract}
This paper proposes fire alarm system by implementing Naïve Bayes Method for increasing smoke classifier accuracy on Internet of Things (IOT) environment. Fire disasters in the building of houses are a serious threat to the occupants of the house that have a hazard to the safety factor as well as causing material and non-material damages. In an effort to prevent the occurrence of fire disaster, fire alarm system that can serve as an early warning system are required. In this paper, fire alarm system that implementing Naïve Bayes classification has been impelemented. Naïve Bayes classification method is chosen because it has the modeling and good accuracy results in data training set. The system works by using sensor data that is processed and analyzed by applying Naïve Bayes classification to generate prediction value of fire threat level along with smoke source. The smoke source was divided into five types of smoke intended for the classification process. Some experiments have been done for concept proving. The results show the use of Naïve Bayes classification method on classification process has an accuracy rate range of $88 \%$ to $91 \%$. This result could be acceptable for classification accuracy.
\end{abstract}

Keywords: Fire Disaster, Fire Alarm System, Internet of Things, Naïve Bayes Classifier

\section{Introduction}

Fires in buildings and houses are very threatening and dangerous for the safety of the inhabitants. In addition, the fire disaster can cause a huge loss of material and non-material impact. Therefore, a form of fire disaster prevention for residents is required by designing a fire early warning system. Fire early warning system is intended to support the efficiency of time in evacuating the residents of the house. In general, this system is known as fire alarm system. Fire alarm system has a very significant role in the function of detecting and providing quick response to the threat of fire disaster for residents of the house [1].

In the present era the security of a home building becomes an important thing. Monitoring mechanism on fire alarm system is one method that can minimize the threat to fire disaster. However, there are still a lot of fire alarm automation systems using traditional cables as a medium of integration between detector sensors with system parts which will potentially be a constraint of the cost and maintenance factor of the system [2]. In addition, the existence of some failure of the system such as false alarm on the fire alarm system can cause a very fatal impact related to the delivery of information on fire threat indication resulting in the potential misunderstanding of information delivery to the occupants.

One of an emerging technology, that currently become trend, is Internet of Things (IoT). Literally, this technology will connect everything throughout Internet. Some application have been developed based on loT platform such as [3][4][5]. In the same way, loT could become solution for transmitting data from fields to the server through Internet.

For solving fire threat problems, the solution needed is to design a fire alarm system based on internet of things (IoT) by implementing Naïve Bayes classification as a machine learning technique. The Naïve Bayes classification method is used in the design of tools to predict the degree of fire threats from smoke sources by utilizing numerical data taken on sensors. The Naïve Bayes classification method has advantages in modeling and a good degree of accuracy in use in training datasets [6]. The Fire Alarm System uses ESP32 microcontroller equipped with a buzzer, an MQ-7 and MQ-135 gas sensor, along with a DHT-11 temperature and humidity sensor.

Based on the background, there are identification problems such as how to implement the fire alarm system based on loT by using Naïve Bayes classification method which has the function

Iqbal, A., Abdurohman, M., \& Putrada, A. (2018). Increasing Smoke Classifier Accuracy using Naïve Bayes Method on Internet of Things. Kinetik: Game Technology, Information System, Computer Network, Computing, Electronics, and Control, 4(1). doi:http://dx.doi.org/10.22219/kinetik.v4i1.704

Receive September 20, 2018; Revise November 01, 2018; Accepted November 10, 2018 
of determining the prediction level against the fire threat along with the source of smoke type and besides seeing the performance of the system on the fire alarm system.

In the identification of the problem that has been explained, that there are limitations of problems in research such as the design on the tool contains gas sensors, temperature and humidity, and buzzer as a sound marker of danger. Tests on the fire alarm system are done in one room and the test distance between the sensors and smoke as long as $10 \mathrm{~cm}$. In addition, the test used five sources of smoke type consisting of non-smoking conditions (normal), cigarette smoke, vaporizer smoke, waste paper smoke and charcoal smoke.

The finding of this paper is the effecive classification process based on Naïve Bayes classification method that functions in determining prediction level of fire threat along with smoke source by utilizing data from sensors.

\section{Research Method \\ 2.1 Fire Alarm System}

This research is an advanced of previous research, where this research focuses on making a fire alarm system design tool to find effective and efficient performance in handling the threat of fire disaster. Previous paper discusses the monitoring of fire detection systems using wireless sensor methods designed for security design for disaster fire in a building [7]. However, the journal only implements real time monitoring without any learning techniques on fire detection systems. Another paper discusses the design of smoke and heat detection system to monitor the conditions in a closed room in order to find an indication of fire threat. The system design of the journal uses fuzzy logic method in determining the regulation scheme on the sensor related to the indication of fire disaster threat [8].

In addition, there is a research reference to the journal "Implementation of Naïve Bayes Classification Methods in Predicting Domestic Household Utilization Usage" written by Alfa Saleh In the Year 2015, where the journal describes the mechanism of prediction of the magnitude of the use of household electricity using the method of data classification Naïve Bayes by utilizing supporting parameter data. The result of the conclusion of the journal is that the use of Naîve Bayes data classification method can predict the accuracy level on the magnitude of household electrical usage with percentage value above $75 \%$ [9].

Therefore, the authors undertake the development of research from the journals mentioned by adding the concept of loT with the aim to provide wider accessibility control and quick response in the action of fire prevention [10]. In addition, the authors replace the fuzzy logic method with the Naïve Bayes classification method intended to be able to perform in the search for predictive level against the threat of danger of fire indication. The Naïve Bayes classification method is used by utilizing data from active sensors. The data is used as a reference for data processing in using the Naïve Bayes classification method in finding the size of the prediction level against fire threats. The fire alarm system uses microcontroller and detection sensors such as, gas sensor, temperature sensor, and humidity sensor.

The Naïve Bayes method is a simple probabilistic classification method that computes a set of probability sums taken from a combination of dataset and frequency values. The advantage of using Naïve Bayes method is to utilize the number of small-scale training data for estimating in data classification process [9]. Further explanation relates to the formulation of Naïve Bayes classification that there is an analytical process determining the appropriate class of samples. And following the process of classification Naïve Bayes [9].

We proposed a fire alarm system for enhancing the performance of the former system. The renewal of the system design is in the form security aspects which uses the result of fire threat prediction level and smoke source. Figure 1 . Shows the description of the fire alarm system.

The fire alarm system has a function to be able to detect the state around the environment of the system device. On system devices there are gas sensors, temperature sensors, and humidity sensors. The sensor serves to detect a fire threat with an object that has a source of smoke, especially fire. Fire elements are ensured that there is smoke and heat that affect the temperature and humidity levels in the room, hence the reason for the sensor's selection. The Sensors' function are to provide input value in accordance with the unit of functionality on the sensor.

The input value is governed by NodeMCU ESP32 which can transmit on ThingSpeak platform which can be integrated with MATLAB application in data processing using Naïve Bayes classification. After going through the data processing, the ThingSpeak output value is sent to the

KINETIK Vol. 4, No. 1, February 2019: 19-26 
NodeMCU ESP32. Fire alarm system can activate buzzer with alarm sound when there is danger signal detected by system device.

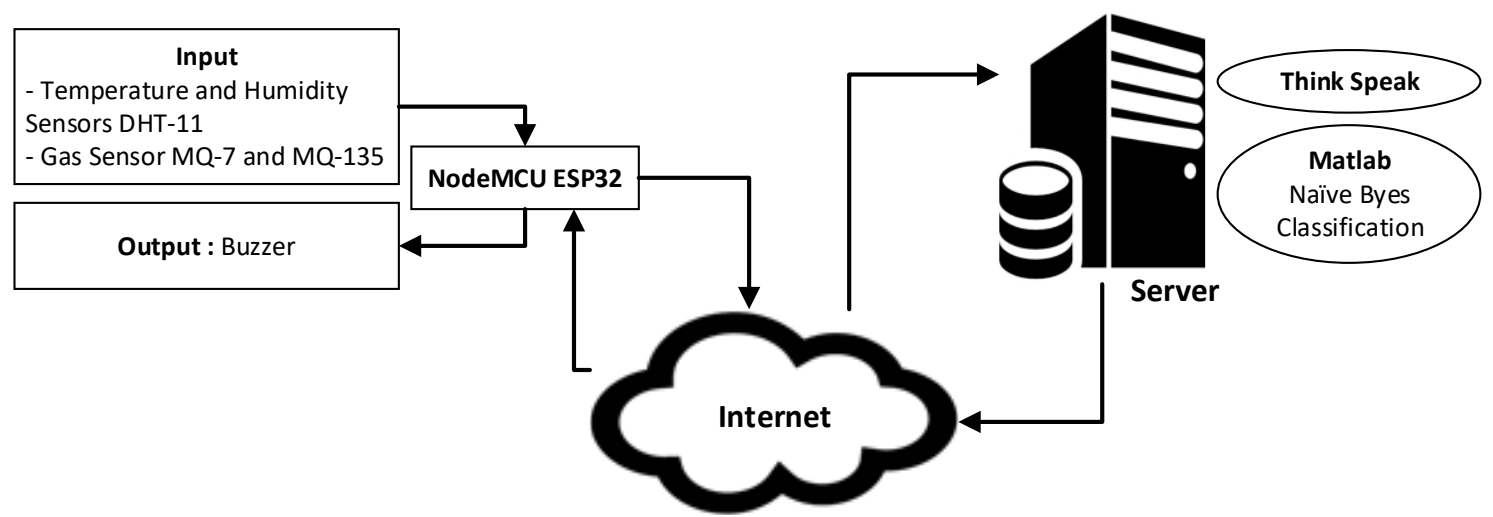

Figure 1. Fire Alarm System Diagram.

The fire alarm system has many functions such as: The system device is able to detect objects of fire element in the form of smoke, temperature and humidity, system devices can be integrated with the ThingSpeak platform and ThingSpeak can be integrated with MATLAB which can process the input values of sensors using the Naïve Bayes classification, users can monitor data from the ThingSpeak platform that has a predicted rate of fire threat and smoke source and NodeMCU ESP32 serves as the input and output data path on the server along with the system device. In the fire alarm system, there is a flow diagram of the system that shows how the system tools work with a series of processes in stages. Figure 2. Shows the flow diagram of the system.

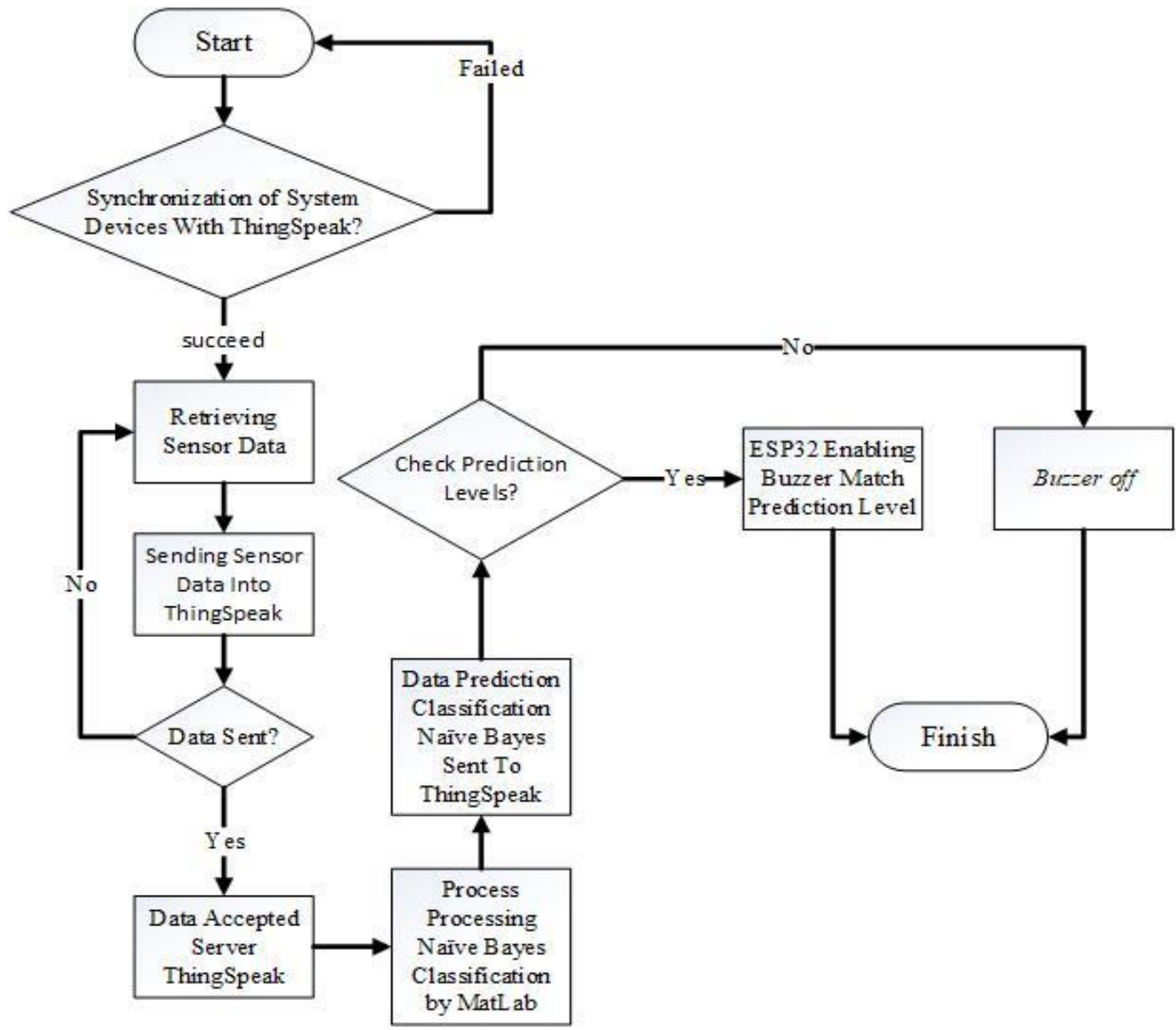

Figure 2. Flow Diagram Fire Alarm System. 
ISSN: 2503-2259; E-ISSN: 2503-2267

In this paper, there are many hardware devices and their's specifications that used in system implementation. Table 1 shows the hardware system specifications. In addition to the used hardware, the software to support the research are as the specifications below: Windows Operating System 10, RapidMiner, Tools: Arduino IDE, ThingSpeak and MATLAB.

Table 1. Hardware System Specifications

\begin{tabular}{lll}
\hline \multicolumn{1}{c}{ Hardware } & Hardware Type & \multicolumn{1}{c}{ System Hardware Functionalities } \\
\hline Microcontroller & NodeMCU ESP32 & $\begin{array}{l}\text { The system controller device and as the } \\
\text { sensor data transmitting medium on } \\
\text { ThingSpeak via WiFi. } \\
\text { Temperature Sensor }\end{array}$ \\
$\begin{array}{l}\text { and Humidity } \\
\text { Sensor Gas }\end{array}$ & $\begin{array}{l}\text { As a temperature and humidity detector that } \\
\text { adjusts to the indication of fire element. }\end{array}$ \\
Buzzer & $\begin{array}{l}\text { MQ-7 and MQ-135 } \\
\text { Passive/Active a detector on the smoke element. } \\
\text { Buzzer }\end{array}$ & $\begin{array}{l}\text { As a danger warning system by issuing a } \\
\text { loud noise. }\end{array}$ \\
\hline
\end{tabular}

\subsection{Data and Testing Scenarios}

The research data was taken using a DHT-11 temperature and humidity sensor, and a couple of gas sensors, MQ-7 and MQ-135. The data collected are data of five types of smoke, including no smoke (normal), cigarette smoke, vape smoke, garbage paper smoke and charcoal smoke. Each type of smoke is taken 100 times in which all data amounts to 500 data. At 500 the data is divided into 300 data for training and 200 data for testing. The data is used to apply the Naïve Bayes classification process to the system device in finding the accuracy of the threat of fire and the source of smoke. The Naïve Bayes classification testing process uses RapidMiner and MatLab tools that are integrated with ThingSpeak. The collection of training and testing data are given in the form of scatter multiple graphs in Figure 3.

In this paper various functionalities of microcontroller, sensor and system buzzer on fire alarm system device are tested. This is done by looking at the performance in accordance with the needs of the system. In addition to testing system tools, the research tests the application of Naïve Bayes classification process to the system by using ThingSpeak server integration in data retrieval and processing. Therefore, this research does the test with staged scenarios, which are as follows:

1. Fire alarm system device test.

This system uses DHT11 temperature and humidity sensors, gas sensors MQ-7 and MQ135. The sensors were tested against five types of smoke, which are the smoke-free condition (normal), cigarette smoke, vape smoke, burnt paper smoke and charcoal smoke. The reason for the use of vape smoke is to try the value of the smoke content in the test against the gas sensor. The ESP32 microcontroller is integrated into the Thingspeak platform along with the sensor devices and the buzzer. The configuration applied to the buzzer is done by setting the output value to become a danger signal for smoke conditions.
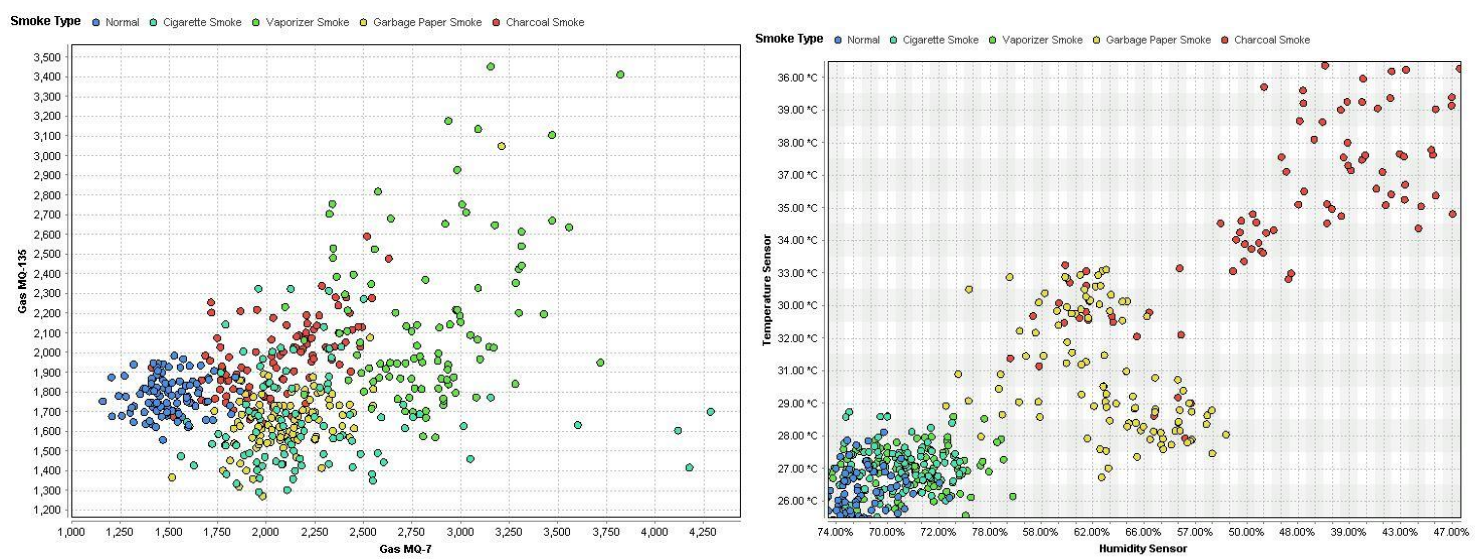

Figure 3. Scatter Chart of 500 Sensor Data of the Fire Alarm System 
2. Naïve Bayes classification process test.

System collects sample data on the system device from the detection of sensors in the form of numerical data as much as 500 data with five different smoke types. The research then divides the data where 300 of the data is for training data and the other 200 data is for testing data. The data were tested with Naïve Bayes classification application provided by RapidMiner tool and MATLAB application. The Naïve Bayes classification process is aimed at finding the predicted rate of fire threats and smoke sources.

3. Overall Performance Test

In this stage the research tests the functionality on the condition of the tool device that can function from the level of sending and receiving input data from the ThingSpeak server and receive output data from ThingSpeak in the form of predicted results processed with MatLab which can activate Buzzer with the sound signal value that has been adjusted with the results prediction. The metrics tested are accuracy and delay. Accuracy is tested by comparing real results with theoritical results and delay is tested by measuring the time difference between reaction of actuators towards sensing inputs.

\section{Results and Discussion}

\subsection{Sensor Test Results on Fire Alarm System}

In the sensor testing the researchers observed the performance of sensor functionality which can be integrated with the ThingSpeak platform by using Arduino IDE software. Sensors contained in the fire alarm system consist of gas sensors, MQ-7 and MQ-135 and a temperature and humidity sensor, DHT-11. Observations over this test results in a successfull performance by having the sensor results contained in Figure 4.

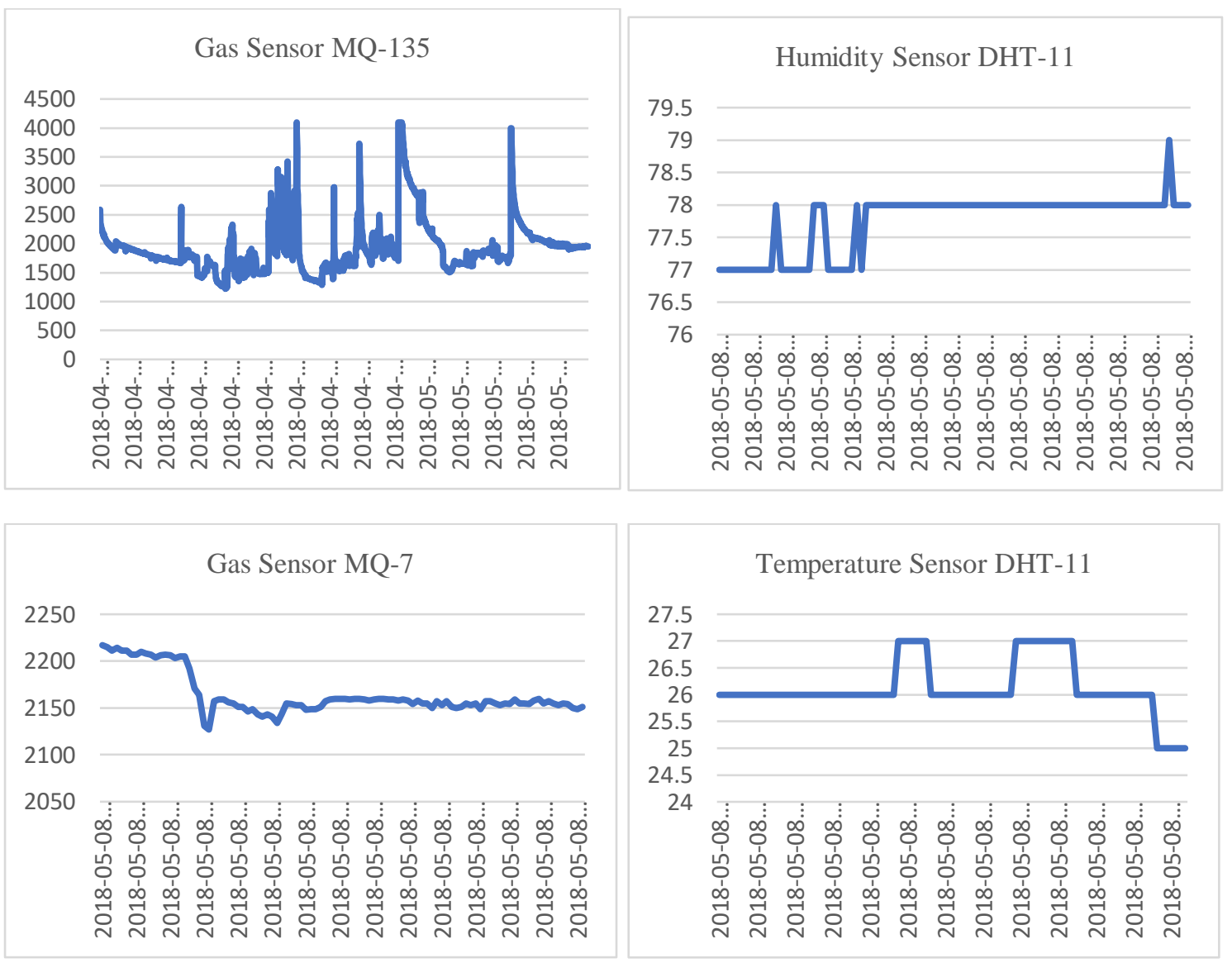

Figure 4. Gas Sensor MQ-7 MQ-135 and Temperature Sensor DHT-11 results. 


\subsection{Naïve Bayes on RapidMiner Test Results}

Test results obtained on the application of Naïve Bayes classification process using RapidMiner from 300 training data has the result of mean and standard deviation value which is used for the classification process. The mean and standard deviation of 300 training data can be shown in Figure 5. The results of mean and standard deviation are used for the classification process on 200 data testing which then after the completion of the process the classification results emerge in the form of threshold model and accuracy level value. The results of this classification can be seen in Figure 6 .

\begin{tabular}{|c|c|c|c|c|c|c|}
\hline Attribute & Parameter & Normal & Cigarette Smoke & Vaporizer Smoke & Garbage Paper S... & Charcoal Smoke \\
\hline Humidity Sensor & mean & 74.983 & 69.850 & 72.717 & 63.883 & 51.967 \\
\hline Humidity Sensor & standard deviation & 0.129 & 0.732 & 1.552 & 2.624 & 9.681 \\
\hline Temperature Sensor & mean & 26 & 27 & 27 & 29.667 & 33.667 \\
\hline Temperature Sensor & standard deviation & 0.001 & 0.001 & 0.001 & 0.914 & 3.398 \\
\hline Gas MQ-7 & mean & 1469.117 & 2345.350 & 2769.967 & 2097.750 & 2070.933 \\
\hline Gas MQ-7 & standard deviation & 22.263 & 511.215 & 358.121 & 210.925 & 263.814 \\
\hline Gas MQ-135 & mean & 1787.250 & 1652.150 & 2280.300 & 1670.783 & 2000.200 \\
\hline Gas MQ-135 & standard deviation & 11.998 & 247.980 & 376.244 & 207.413 & 176.326 \\
\hline
\end{tabular}

Figure 5. Results Mean Value and Standard Deviation 300 Training Data

accuracy: $91.00 \%$

\begin{tabular}{|c|c|c|c|c|c|c|}
\hline & true Normal & true Cigarette $\mathrm{S} .$. & true Vaporizer S... & true Garbage P... & true Charcoal S... & class precision \\
\hline pred. Normal & 28 & 0 & 0 & 0 & 0 & $100.00 \%$ \\
\hline pred. Cigarette ... & 0 & 40 & 6 & 0 & 0 & $86.96 \%$ \\
\hline pred. Vaporizer ... & 12 & 0 & 34 & 0 & 0 & $73.91 \%$ \\
\hline pred. Garbage ... & 0 & 0 & 0 & 40 & 0 & $100.00 \%$ \\
\hline pred. Charcoal ... & 0 & 0 & 0 & 0 & 40 & $100.00 \%$ \\
\hline class recall & $70.00 \%$ & $100.00 \%$ & $85.00 \%$ & $100.00 \%$ & $100.00 \%$ & \\
\hline
\end{tabular}

Figure 6. Results of Naive Bayes Classification Process on RapidMiner

Based on the classification results of 200 testing data, each smoke has 40 data showing for normal conditions can predict 28 data correctly and 12 normal data have been predicted as vape smoke. For cigarette smoke predictions are all correct but there are 6 vape smokes predicted cigarette smoke. For vape smoke 34 data are predicted correctly and 6 data are predicted as cigarette smoke. The condition of paper waste and charcoal paper can predict the data correctly and accurately so that the result of accuracy level obtained in 200 testing data equal to $91 \%$. However, the test results show that vape smoke has a low class recall and class precision so it impacts on the performance level of prediction accuracy on fire alarm system.

\subsection{Naïve Bayes Test Results on MatLab for Fire Alarm System}

Testing the classification of Naïve Bayes in MatLab is done by observing the type of smoke to see the success of the prediction in each data and observing the average time delay in the experiment when the buzzer is active. The following test data results in Table 2.

It shows the obtained 50 experimental test results data with different types of smoke that 44 data in accordance with the correct status conditions and for 6 data has the wrong prediction so that the accuracy results obtained from all data tested for $88 \%$. Observation testing prediction of each smoke is done by seeing different buzzer signal conditions. Buzzer signals are differentiated, indicating a different smoke for each signal. In addition, the observation for the total time delay average in buzzer activation takes about 22 seconds for the entire experiment. Based on these results vape smoke has a failure in the test with a prediction accuracy level of $50 \%$ of 
the total data vape smoke testing due to the indication of vape smoke content that is not suitable on the use of sensors MQ-7 and MQ-135 so that affects the performance of the system.

Table 2. Result Testing Fire Alarm System with MatLab

\begin{tabular}{ccccc}
\hline Smoke Type & Testing & Succeed & Failed & $\begin{array}{c}\text { Average Delay Time on } \\
\text { Buzzer / Smoke Type (ms) }\end{array}$ \\
\hline Normal & 10 & 10 & 0 & 0 \\
Cigarette smoke & 10 & 10 & 0 & 22487 \\
Vaporizer smoke & 10 & 5 & 5 & 23089 \\
Rubbish Paper & & & & 22145 \\
Smoke & 10 & 9 & 1 & 22732 \\
Charcoal smoke & 10 & 10 & 0 & $22,613.25$ \\
\hline \multicolumn{7}{l}{ Total Average Delay Time All Tests on Buzzer } & \\
\hline
\end{tabular}

\section{Conclusion}

Based on severals testing, the results show that the implementing of Naïve Bayes classification method on fire alarm system could increase an accuracy rate range of $88 \%$ to $91 \%$. System devices have well performed in the delivery of sensor data on the ThingSpeak server.

\section{References}

[1] A. K. Mohan, "Integrating Wireless Sensor Network and Internet of Things for Detecting Fire using Fuzzy Logic," International Journal of Advanced Research in Electrical, Electronics and Instrumentation Engineering. Vol. 2, No. 12, Pp. 6431-6438, 2013.

[2] M. S. P. Patange and M. S. V. Yadav, "Design and Implementation of Automatic Fire Alarm System based on Wireless Sensor Networks," Journal of Emerging Technologies and Innovative Research, Vol. 2, No. 9, Pp. 49-51, 2015.

[3] Abdurohman, M., Herutomo, A., Suryani, V., Elmangoush, A. and Magedanz, T., "Mobile tracking System Using OpenMTC Platform Based on Event Driven Method," In Local Computer Networks Workshops (LCN Workshops), 2013 IEEE 38th Conference, Pp. 856860, 2013.

[4] Herutomo, A., Abdurohman, M., Suwastika, N.A., Prabowo, S. and Wijiutomo, C.W., "Forest Fire Detection System Reliability Test Using Wireless Sensor Network and OpenMTC Communication Platform," In Information and Communication Technology (IColCT), 2015 3rd International Conference, Pp. 87-91. 2015.

[5] Besari, P.A.L., Abdurohman, M. and Rakhmatsyah, A., "Application of M2M to Detect the Air Pollution," In Information and Communication Technology (ICoICT), 2015 3rd International Conference, Pp. 304-309. 2015.

[6] Daniela Xhemali, Christopher J. Hinde and Roger G. Stone, "Naïve Bayes vs Decision Trees vs Neural Networks in the Classification of Training Web Pages," International Journal of Computer Science, Vol. 4, No. 1, Pp. 16-23, 2009.

[7] L. Zhang and G. Wang, "Design and Implementation of Automatic Fire Alarm System based on Wireless Sensor Networks," International Symposium on Information Processing, Pp. 410-413, 2009.

[8] S. Prayogi, M. Yamin and R. Ramadhan, "Perancangan dan Implementasi Prototipe Sistem Pendeteksi Asap dan Panas Pada Ruangan Tertutup Menggunakan Logika Fuzzy Sugeno," SEMANTIK. Vol. 2, No. 2, Pp. 167-176, 2016.

[9] A. Saleh, "Impelementasi Metode Klasifikasi Naïve Bayes Dalam Memprediksi Besarnya Penggunaan Listrik Rumah Tangga," Citec Journal. Vol. 2, No.3, Pp. 207-217, 2015.

[10] F. Xia, L. T, Yang, L. Wang, and A. Vinel, "Editorial Internet of Things," International Journal of Communication Systems, 25, Pp. 1101-1102, 2012. 
KINETIK Vol. 4, No. 1, February 2019: 19-26 